\title{
Saussure frente a seus contemporâneos: uma análise das questões relativas ao sentido nos primeiros capítulos do manuscrito De l'Essence Double du Langage
}

\author{
Maurício Marques Sortica*
}

Resumo: Este artigo investiga o lugar dado ao sentido na elaboração teórica saussuriana no final do século XIX. Assim, analisam-se os primeiros capítulos do manuscrito De l'Essence Double du Langage (SAUSSURE, 1891). Outrossim, compara-se a elaboração teórica do genebrino àquelas de seus contemporâneos (WHITNEY, 2010; PAUL, 1966; BRÉAL, 1992). Por fim, infere-se que Saussure parecia elaborar um constructo teórico colocando o sentido como centro da análise linguística. Infere-se, também, que o linguista parte do pensamento desenvolvido por seus contemporâneos, mas rompe com tal tradição, pensando o sentido sincronicamente e não dando lugar relevante à mudança temporal deste em sua elaboração teórica.

Palavras-chave: Sentido. Estudos saussurianos. Linguística do século XIX. De l'Essence Double du Langage.

\begin{abstract}
This article investigates the place given to meaning in saussurian theoretical elaboration at the end of the nineteenth century. Thus, the first chapters of the manuscript De l'Essence Double du Langage (SAUSSURE, 1891) are analyzed. Moreover, the genebrine's theoretical elaboration is compared to those of his contemporaries (WHITNEY, 2010; PAUL, 1966; BRÉAL, 1992). Finally, one infers that Saussure seemed to elaborate a theoretical construct placing meaning as the centre of linguistic analysis. Besides, the linguist departs from the thought developed by his contemporaries, but breaks with such tradition, thus thinking of meaning synchronically and not giving relevant place to temporal change in his theoretical elaboration.
\end{abstract}

Key words: Meaning. Saussurean studies. 19th-century linguistics. De l'Essence Double du Langage.

Résumé: Cet article étudie la place donnée au sens dans l'élaboration théorique saussurienne à la fin du XIXe siècle. Ainsi, on analyse les premiers chapitres du manuscrit De l'Essence Double du Langage (SAUSSURE, 1891). On compare, aussi, l'élaboration théorique du genevois à celles de ses contemporains (WHITNEY, 2010; PAUL, 1966; BRÉAL, 1992). Enfin, on déduit que Saussure a semblé élaborer une construction théorique plaçant le sens au centre de l'analyse

\footnotetext{
* Doutorando em Estudos Linguísticos pela Universidade Federal de Uberlândia (UFU). Professor da rede privada de ensino de Porto Alegre/RS. http://orcid.org/oooo-0002-8097-3288 / E-mail: mauricio.sortica@ufu.br
}

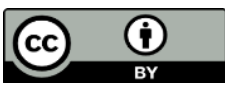

Este artigo está licenciado sob forma de uma licença Creative Commons Atribuição 4.0 Internacional, que permite uso irrestrito, distribuição e reprodução em qualquer meio, desde que a publicação original seja corretamente citada. 
linguistique. Également, il s'écarte de la pensée développée par ses contemporains, mais rompt avec cela en pensant le sens de synchroniquement et en n'accordant pas de place pertinente au changement temporel dans son élaboration.

Mots-clés: Sens. Études saussuriennes. Linguistique du XIX ${ }^{\mathrm{e}}$ siècle. De l'Essence Double du Langage.

\section{O sentido do estudo}

Falar de Saussure, de sua obra e de sua contribuição para o campo dos estudos linguísticos é sempre paradoxalmente instigante e ingrato. Esse sentimento ambivalente se dá, muitas vezes, por causa das várias recepções que a obra saussuriana teve ${ }^{1}$ (e ainda tem) por linguistas e por outros profissionais que têm a linguagem como algo que permeia seu objeto de estudo. De um lado, temos aqueles que tomaram a edição do Curso de Linguística Geral (SAUSSURE, [1916] 1970) e os princípios ali expostos a partir de uma leitura "positivada" (cf. NORMAND, [2000] 2009) como o divisor de águas e o fundador de uma ciência da língua, sem lugar para qualquer coisa que não seja ela; de outro, vemos aqueles que, a partir da descoberta e da leitura de manuscritos com as ideias esparsas do genebrino, contestam a edição do $C L G$ e o consideram como uma "vulgata" (BOUQUET, 2004). Na terceira margem do rio, temos ainda aqueles que simplesmente desconsideram o pensamento teórico de Saussure justamente por, em sua visão, esse não dialogar diretamente com seu objeto de estudo. Em terras brasileiras, essa história não caminha por trilhos muito diferentes.

É interessante notar, entretanto, que, dentre as várias discussões que concernem o papel das teorias de Ferdinand de Saussure dentro dos estudos linguísticos, uma parece ser constante: aquela que tange à importância do sentido dentro do pensamento linguístico do genebrino. Ora, se se compreende, com Flores (2019), que Saussure foi um dos responsáveis por introduzir na linguística de seu tempo a noção de que ela está dentro das ciências e, por conseguinte, dos fatos humanos, e se toma a máxima de Benveniste ([1967] 2017) que diz que "a essência da linguagem é, antes de tudo,

\footnotetext{
${ }^{1}$ A esse respeito, recomenda-se a leitura de De Lemos et al. (2003) e de Silveira (2016).
} 
significar"2 (p. 217), vemos bem que esse problema do sentido é algo extremamente importante para a língua e para a maneira como o homem se insere nela. E é por isso que ela é tomada como pertinente para esta pesquisa, cujo objetivo é dialogar não só com aqueles interessados em historiografia e epistemologia da linguística ou com aqueles que se interessam pelos estudos saussurianos, mas também com todos a quem as noções e conceitos ${ }^{3}$ relativos ao sentido dentro da história das ideias importam. Em vista disso, resgata-se, a seguir, o ponto de vista de autores que transitam por essas áreas do conhecimento.

Em livro que visa a tratar das concepções de sentido ao longo dos estudos filosóficos da linguagem, Guimarães (2005, p. 20)4 afirma que o princípio saussuriano de valor "abre caminho para a exclusão do mundo e das relações de significação". Para ele, isso implica excluir aquilo que é visto como "próprio da significação" (GUIMARÃES, 2005, p. 23), já que o dito “corte saussuriano”, para o autor, significa excluir dos estudos da linguagem "o referente, o mundo, o sujeito e história" (2005, p. 20). Por outro lado, Simon Bouquet, um dos editores dos Escritos de Linguística Geral (SAUSSURE, [2002]5 2004), afirma que "a abordagem de Saussure em relação à semântica passou extremamente despercebida" 6 (BOUQUET, 2004, p.205) por aqueles que leram as produções do mestre genebrino. No entanto, segundo o filósofo francês, embora não se possa dizer que o pai da linguística moderna tenha desenvolvido uma teoria do sentido, há, em seus escritos "indícios extremamente claros [...] que apontam na direção de tal teoria”7 (BOUQUET, 2004, p.205).

\footnotetext{
${ }^{2}$ No original: "[...] le propre du langage est d'abord signifier".

3 Os termos "noção" e "conceito", aqui, são tomados no mesmo sentido empregado por Coelho (2019), para quem esse se vincula a uma elaboração teórica mais concreta e acabada, enquanto aquele diz respeito a algo mais abstrato e/ou impreciso.

${ }^{4}$ É importante notar que, embora a primeira edição da obra referida de Guimarães tenha sido publicada antes das descobertas mais recentes dos manuscritos saussurianos, todas as suas reedições e reescrituras até hoje não parecem contemplar tais descobertas e sua direta influência na leitura do pensamento de Ferdinand de Saussure. De qualquer maneira, acredita-se que, mesmo sem acesso aos manuscritos, uma leitura atenta do Curso de Linguística Geral (SAUSSURE, 1970) não permitiria tal interpretação.

${ }^{5} \mathrm{~A}$ data entre colchetes refere-se à edição francesa, que foi traduzida e publicada no Brasil em 2004. A obra, contudo, reúne textos saussurianos de diferentes momentos.

${ }^{6}$ No original: "Saussure's approach to semantics has gone largely unnoticed".

${ }^{7}$ No original: "[...] there are extremely clear suggestions [...] which point the way towards such theory".
} 
Mais recentemente, Loïc Depecker, diretor de pesquisas em ciências da linguagem da Universidade Sorbonne Nouvelle, afirma, ao examinar as notas dos alunos de Saussure que culminaram na edição do Curso de Linguística Geral (SAUSSURE, 1970), que "a noção de sentido remete, então, ao valor e valor remete ao Sistema. Mas o inverso é igualmente verdadeiro" (DEPECKER, 2012, p. 77). Essa afirmação, que vai ao encontro do que afirma Bouquet (2004), encontra eco em Flores (2019), que, ao discorrer sobre as relações entre forma e sentido como um problema geral da linguística, observa que a teoria saussuriana "se projeta numa perspectiva semântica de entendimento de cada valor linguístico" (FLORES, 2019, p. 336), de modo que a teoria do valor "dá contornos a uma linguística que coloca o sentido no centro, o que implica a constituição de um objeto semântico" (2019, p. 366).

Como se pode notar, ao se tratar da teoria saussuriana, especialmente naquilo que diz respeito ao sentido, costumava-se pensar que houvera a exclusão do sentido, por parte do linguista genebrino, no pensamento que funda a linguística como ciência, aquilo ainda conhecido por muitos como o "corte saussuriano". Essa visão, conforme ensina Normand (2009), é fruto de uma leitura "positivada" da obra póstuma de Saussure. Mesmo assim, leitores mais atentos do autor veem nela, explorando ou não os manuscritos que lhes deram origem, o gesto fundante de uma teoria que abarca o sentido. É desse modo que se posiciona este trabalho.

Partindo, portanto, do pressuposto de que existe, sim, um lugar dado ao estudo do sentido no pensamento saussuriano, este artigo propõe-se a investigar tal noção na elaboração da teoria saussuriana no final do século XIX. Isso se deve, em primeiro lugar, ao fato de que, se existe uma teoria voltada ao sentido em Saussure, ela deverá ter tido um início em termos epistemológicos. Esse início, se é que se pode exatamente pontuar algo no tempo quando se trata de um pensamento em constante (re)construção como o do linguista genebrino, pode nos dar indícios da filiação intelectual de Saussure em relação aos linguistas de sua época, o que, para o estudioso das histórias das ideias linguísticas, pode apontar como o genebrino se liga, adapta e rompe com aquilo que era dito em seu tempo.

Em segundo lugar, investiga-se a construção do pensamento de Saussure com vistas a identificar possíveis mudanças de noções teóricas ao longo de seu trabalho. 
Nesse sentido, elencam-se, como corpus de análise, os primeiros capítulos do manuscrito De l'Essence Double du Langage (SAUSSURE, 1891), haja vista esse ser um dos manuscritos mais conhecidos entre os estudiosos do pensamento saussuriano e aquele em que começam a se construir as noções sobre linguística geral que culminariam, cerca de uma década depois, nos três cursos que Saussure ministraria na Universidade de Genebra. Além disso, esses capítulos já trazem uma ideia geral das ideias em gestação a respeito do sentido no referido manuscrito.

Dessa maneira, pode-se dizer que este trabalho pretende, enfim, investigar como a noção de sentido é construída no manuscrito De l'Essence Double du Langage. A partir disso, busca-se entender a relação entre as noções de valor, significação, uso e sentido na construção do pensamento saussuriano. Ademais, pretende-se relacionar tais noções com aquelas desenvolvidas nos estudos da linguagem contemporâneos a Saussure, de modo a ver filiações e rupturas do genebrino com o pensamento de seu tempo.

Ao examinar-se um manuscrito, entretanto, vê-se que o texto estabelecido passa por inúmeras reformulações, marcadas por rasuras, incisos, entre outros elementos. Assim, a fim de compreender as marcas do pensamento saussuriano, faz-se mister entender não apenas aquilo que Saussure escreveu, mas como Saussure escreveu (SILVEIRA, 2007). Por isso, além de prestarmos atenção ao conteúdo do texto per se, é necessário ver como isso se dispõe em seu texto, algo que só pode ser acessado no manuscrito e pelo manuscrito. Nesse sentido, surge um outro objetivo para este trabalho: colocar em relevo o pensamento linguístico saussuriano como algo em constante formação, recorrendo-se às rasuras produtivas dentro do manuscrito analisado como indicativo deste percurso.

Para levar a cabo o projeto deste artigo, então, primeiramente, analisa-se como se davam os estudos linguísticos à época de Saussure, especialmente no que tange ao lugar dado para o sentido nesses estudos. Após isso, baliza-se o estudo e apresenta-se, de fato, trechos do manuscrito a ser analisado, reproduzindo-os e transcrevendo-os. Daqui, procedem a discussão das análises feitas e o ponto de encontro com os objetivos propostos. Por fim, parte-se para as considerações finais deste artigo, em que retomamos as perguntas que nortearam este trabalho e as respostas a elas, ainda que se tenha consciência de que são o objeto-resposta a uma pergunta-ponto de vista. 


\section{O estudo do sentido na linguística do século XIX}

Os estudos linguísticos, no hiato que compreende o final do século XVIII e o século XIX como um todo, apresentaram grande evolução e discussão em torno de seu objeto. Do surgimento de escolas que primavam por aspectos teórico-metodológicos distintos a concepções que misturavam filosofia e ciência de base biologizante, esse período foi bastante fecundo no que diz respeito aos estudos das línguas e das partes que as compunham.

Hermann Paul (1846-1921), linguista, crítico e historiador da ciência linguística da época, publica em 1886 a primeira versão da obra Princípios Fundamentais da História da Língua (PAUL, [1886] 1966), na qual explora os trabalhos feitos nos séculos XVIII e XIX. Para ele, as concepções linguísticas que se importam apenas com uma gramática descritiva e com suas abstrações não darão conta de "uma visão científica da vida da língua" (1966, p. 34). No entanto, essa preocupação tem um lugar definido: aquele da visão histórica e psicológica da língua, estudando-a em suas mudanças e entendendo-a como expressão do pensamento humano, característica do movimento dos neogramáticos ${ }^{8}$. Assim, coloca que as ideias fazem parte do subconsciente do falante, tendo sua origem no meio ambiente, fruto dos diferentes usos de uma palavra ou expressão. Nesse sentido, separa o estudo dos fatos fonéticos da língua daquele dos fatos semânticos, entendendo o estudo da modificação das formas como isolado dos relacionados às mudanças históricas do sentido de uma palavra. No entanto, quando versa sobre o que chama de "mutação semântica" (PAUL, 1966, p. 83), o alemão afirma que, ao contrário do que acontece com as formas fonéticas, o surgimento de uma forma com nova significação não exclui aquela em uso, de modo que ambas convivem lado a lado.

\footnotetext{
${ }^{8}$ Para maiores informações sobre a Gramática Comparada e o movimento dos neogramáticos, ver Câmara Jr. (2021).
} 
Ainda no que tange às noções de sentido, Paul (1966, p. 83) classifica a significação das palavras como usual e ocasional, sendo essa o uso individual de um vocábulo enquanto aquela seria o uso de uma palavra dentro de uma comunidade linguística. Sobre isso, afirma que só é possível reconhecer a relação de origem de uma palavra a partir de seu estudo histórico (PAUL, 1966). Além disso, menciona as relações de significação restritas ao mundo concreto, ao citar o uso de pronomes, e a importância do contexto em que as palavras aparecem, já que esse pode modificar sua interpretação. Dessa forma, embora traga conceitos que são importantes até hoje no que concerne ao estudo da significação, o linguista alemão restringe sua investigação semântica a uma abordagem histórica que se interessa muito mais pelas trocas e diferenças de uso das palavras ao longo dos tempos em estágios diferentes de língua do que por pensar o sentido na língua em seu uso sincrônico.

Algumas das obras referidas por Paul (1966), no que diz respeito à questão do sentido, são aquelas de Michel Bréal (1832-1915). Professor de gramática comparada no Collège de France, Bréal foi colega de Saussure, por quem tinha muita estima. Seu Ensaio de Semântica (BRÉAL, [1897] 1992) é considerado uma obra essencial em relação aos estudos do sentido na época, por reunir o pensamento desse autor, considerado hoje o “pai da semântica”. Segundo sua pesquisa, é a vontade coletiva que é responsável pelas mudanças semânticas na língua, já que o que constitui a linguagem ${ }^{9}$ é "o consentimento de muitas inteligências" e o "acordo de muitas vontades" (1992, p. 197). Embora essas vontades, sobre as quais versa Bréal, tragam à língua um sujeito, sempre concebido em seu aspecto social, de massa, elas estão sensivelmente ligadas ao caráter histórico da pesquisa linguística, já que, para o autor, o que interessa ser investigado é a história da "ciência das significações" e não aquela da "ciência dos sons" (1992, p. 20), conforme vimos ser também costume à sua época. Mesmo assim, algo chama a atenção na teorização brealina - o fato de ele afirmar que "o povo não tem porque remontar ao passado: ele só conhece a significação do momento” (BRÉAL, 1992, p. 187). Isso traz várias implicações para o pensamento do sentido em sua obra. Seguem-nas.

\footnotetext{
9 Aqui utilizam-se os termos "língua" e "linguagem" indistintamente, haja vista o fato de que, para os autores citados, não parece haver distinção teórica entre as palavras.
} 
Em primeiro lugar, dizer que a massa falante só conhece o significado de uma palavra no momento pode significar entender a língua em seu uso, situada e que a história das significações, como ele mesmo se propõe a estudar, seria algo que interessa e tem muito mais utilidade ao linguista do que ao falante. Seguindo essa linha de raciocínio, poder-se-ia dizer que, para o semanticista, os significados não são dados de antemão, o que, em outras palavras, seria afirmar que aquilo que se diz é, em certo aspecto, arbitrário. Sobre isso, o autor defende que, em seu aspecto semântico, a palavra "é uma transposição de realidades por meio de signos particulares dos quais a maior parte não corresponde a nada de real" (BRÉAL, 1992, p. 204), de modo que "não se esgotou tudo o que se pode dizer do sol quando se disse que ele é brilhante [...] porque não se pode dizer do sol que ele brilha quando se esconde" (p. 123). Ou seja, os signos de uma língua não podem apreender tudo o que é real, tampouco representá-lo, sendo aquilo que se faz com a língua em determinado momento - sempre histórico para Bréal - o que definirá a significação de um elemento linguístico.

É interessante, em segundo lugar, notar o que Bréal coloca em seu Ensaio de Semântica em relação à posição de um elemento em um sintagma. Para o pesquisador, “as palavras são colocadas cada vez num meio que lhe determina antecipadamente o valor" (1992, p. 104). Veja-se aqui que o termo "valor" aparece como algo determinado pela posição em que dada palavra é colocada, de modo que se modificará se for colocado em outra posição sintagmática. Nesse sentido, vê-se coerência no que se refere ao pensamento não indexal do pai da semântica, já que a significação não está na natureza ou em um objeto e, sim, na posição que dado elemento ocupa em uma relação presencial com outros elementos. Sobre isso, exemplifica dizendo que "logo que uma palavra entra em uma locução, seu sentido particular e individual é apagado para nós" (BRÉAL, 1992, p. 189). Assim, pode-se dizer que, para Bréal, os elementos linguísticos são arbitrários em relação aos objetos no mundo, mas ainda carregam um caráter positivado, já que pressupõem um sentido particular e individual, objetos da pesquisa histórica em semântica, e que se confirmam ou não em determinada configuração sintática.

Anterior às obras citadas, mas de suma importância para a construção do pensamento de Ferdinand de Saussure, a obra de William D. Whitney (1827-1894), linguista e filólogo estadunidense, é referenciada pelo genebrino tanto no Curso de 
Linguística Geral quanto na edição dos Escritos de Linguística Geral. Nesse sentido, Saussure tece comentários sobre aquilo que é dito pelo filólogo em A Vida da Linguagem (WHITNEY, [1875] 2010), ora concordando com as concepções lá apresentadas, ora criticando-as. Sobre as questões relativas ao sentido, especificamente, o norteamericano argumenta que a mudança da semântica das palavras relaciona-se com o desenvolvimento da linguagem. Nesse sentido, afirma que "os velhos elementos da linguagem são continuamente aplicados a novas utilizações, sem que sua significação original represente algum obstáculo e cause alguma confusão" (WHITNEY, 2010, p. 85). Daqui, embora se possam inferir resquícios de uma visão evolucionista e biologizante da língua, no sentido de que se a concebe como algo que nasce, desenvolve-se e morre, sendo as mudanças de sentido de um dado linguístico ao longo do tempo representaria seu desenvolvimento, Whitney parece ir adiante desse pensamento, já que menciona a “convivência” mútua de sentidos referentes a dada palavra, pensando-as dentro de um grupo social. Desse modo, para ele, se uma comunidade de falantes necessita expressar uma nova ideia, uma nova forma e uma nova significação serão criadas para dar conta disso; por sua vez, diz que "quando uma ideia se perde, a palavra que a exprimia se perde com ela" (WHITNEY, 2010, p. 104).

Além de, já como Bréal (1992), pensar a linguagem como uma manifestação de um conjunto de falantes, Whitney (2010), dentro de tal comunidade, acredita que "há sempre, e em toda a parte, uma ideia que precede a palavra” (p. 136). Essa visão vai além daquela cultivada em seu tempo, de que a linguagem expressa o pensamento. Assim, se uma ideia preexiste a uma palavra, o pensamento viria antes, e a linguagem seria uma derivação, ainda que jamais transparente, desse. No entanto, essa concepção do norteamericano parece se preocupar tão somente com o nome dado às coisas pelo homem, já que, para o filólogo, "todo ato de nomenclatura é precedido de sua concepção; a palavra surge tão logo sua necessidade é sentida. Ela pode se produzir antes mesmo da consciência dessa necessidade" (WHITNEY, 2010 p. 138). Assim, por mais que Whitney veja a linguagem e sua mudança como propriedades da sociedade - do que se pode inferir que os sentidos nela veiculados também o são -, há ainda, em seu pensamento, uma influência muito forte de tradições que pensam a língua como mera nomenclatura. 
Em suma, em uma vista de olhos, pode-se dizer que a questão do sentido na linguagem era, sim, discutida entre o final do século XVIII e o século XIX. No entanto, a principal preocupação de tais discussões eram aquelas ligadas à dita "evolução" e à mudança do sentido, como se veem nas análises sintetizadas por Paul (1966). Nessas análises, compreende-se a língua como a transmissão pura do pensamento e a mudança de sentido em um vocábulo (sempre analisado historicamente) representaria a mudança de pensamento de uma dada comunidade linguística.

Há, entretanto, dissidentes das concepções normalmente atribuídas aos estudos linguísticos na cúspide da modernidade, visto que Bréal (1992) e Whitney (2010), em suas obras, conseguem ver o caráter arbitrário e convencional da linguagem. Esse entende a convenção da relação som e ideia (WHITNEY, 2010); aquele vai mais além e compreende a relação arbitrária da linguagem em relação ao mundo (BRÉAL, 1992). Mais do que isso, ambos veem que a linguagem pertence àqueles que a falam e que o sentido muda por causa dessa comunidade falante, o que, além de colocar os estudos linguísticos dentro das ciências sócio-históricas, desloca as impressões do falante sobre a língua que fala para um ponto mais destacado nas análises da língua.

\section{Sobre a essência dupla da linguagem: apresentação e considerações teórico- metodológicas}

O manuscrito saussuriano conhecido como De l'Essence Double du Langage é uma obra que, segundo os pesquisadores Chidichimo e Gambarara (2008), começou a ser escrito pelo genebrino nos últimos meses de 1891 e que teve sua escrita continuada por bastante tempo. Isso se deu devido ao fato de Saussure, em seu processo de escritura, ter adicionado constantemente novas reflexões a seu projeto de livro, relendo-o, corrigindo-o e categorizando suas partes (cf. CHIDICHIMO; GAMBARARA, 2008, p. 113). Ele é composto por 274 folhas agrupadas e catalogadas por Rudolf Engler na Biblioteca de Genebra em 1996. 
É interessante notar, no Essência Dupla, dois aspectos em especial: aquele que diz respeito a seu conteúdo e o que concerne à sua forma. O primeiro deles, explica Silveira (2013), faz o manuscrito ser "imensamente atraente [...], pela força de uma escrita que margeia os contornos do intocável na língua” (p. 23). Explica-se: aquilo que Saussure escreve nas folhas desse manuscrito dialoga diretamente com a linguística de seu tempo, de modo que o genebrino tenta definir conceitos que estavam em voga durante o período em que se dedicou a esses escritos, mas muitas vezes titubeando, rasurando passagens inteiras e constantemente reformulando aquilo que ali escrevia. É esse caráter do conteúdo, da sua constante revisão e especialmente da marca que esses aspectos deixam que são quase intocáveis. Utilizando as palavras de Silveira, nessas marcas, vê-se a divisão "entre o saber já estabelecido e aquele que ele não pode dizer" (2007, p. 118). O aspecto da forma e da organização do manuscrito, entretanto, também são de uma particularidade interessante.

Dividido em 29 capítulos, que, por sua vez, foram subdivididos em letras em um esforço de Engler de colocar ordem num emaranhado de folhas com formatos, grafias e cores diferentes, o Essência Dupla apresenta "uma unidade bastante discutível, [que] ainda merecerá alguns debates no decurso dos estudos dos manuscritos de Ferdinand de Saussure" (SILVEIRA, 2013, p. 25). Embora o objetivo deste trabalho não seja se deter na controvérsia da organização do manuscrito, faz-se mister colocar que, para Sofia ${ }^{10}$ (2012), "conhecem-se, ao menos, quatro versões da transcrição feita por Engler de $D a$ Essência Dupla da Linguagem"” (p. 38) e que uma dessas versões, aquela catalogada na Biblioteca da Universidade de Genebra e com a qual se trabalha neste artigo, tem, inclusive, um duplo - o AS 372 e o AS 372 bis $^{12}$. Destarte, as diversas possibilidades de organização do manuscrito, feitas a partir da numeração de folhas e de assuntos que não foram, necessariamente, pensados por Saussure, podem permitir a quem lê diversas

\footnotetext{
${ }^{10}$ Por mais contraditório que possa parecer, a utilização dos trabalhos de Bouquet (2004) e Depecker (2012), autores notadamente a favor do processo de edição dos manuscritos saussurianos e, logo após, daquele de Sofia (2012), que se posiciona contrariamente a tais edições da maneira que foram feitas por Engler e Bouquet (SAUSSURE, 2004), enfatiza-se o fato de que os três estudiosos, mesmo em suas divergências, veem na obra do linguista genebrino um lugar para uma teoria do sentido.

${ }^{11}$ No original: "On a connaissance d'au moins quatre versions de la transcription faite par Engler de 'De l'Essence Double du Langage".

${ }^{12}$ Agradece-se pela cessão de cópia do referido manuscrito por parte da professora Eliane Silveira (PPGEL/UFU), adquirido por ela junto aos arquivos da Biblioteca de Genebra.
} 
interpretações sobre a ordem e a construção do pensamento saussuriano dentro de tal documento. Mesmo assim, mergulhar nesse discurso é necessário àqueles que pretendem pesquisar mais a fundo aquilo relativo à constituição das ideias linguísticas de Saussure.

Dessa forma, a fim de analisar trechos do manuscrito De l'Essence Double du Langage para ver as considerações do genebrino sobre as noções ligadas ao campo do sentido, faz-se mister não apenas entender o que Saussure escreveu, mas como ele o fez (cf. SILVEIRA, 2007). Nesse sentido, é necessário verificar como o conteúdo dispõe-se em seu texto, algo que só pode ser acessado no manuscrito e pelo manuscrito. Por isso, utiliza-se nas análises deste artigo a versão AS 372bis do documento.

Opta-se também pela organização bis de Engler, uma vez que essa é a que é utilizada na edição dos Écrits de Linguistique Génerale, feita pelo próprio Engler e pelo filósofo Simon Bouquet (SAUSSURE, 2004 ${ }^{13}$ ) e, portanto, de maior conhecimento do público leitor de Saussure em geral. Entretanto, atenta-se para of fac-símile das passagens que interessam a este trabalho devido ao fato de a edição supracitada não atender aos objetivos já aqui colocados. No caso da edição de Engler e Bouquet (SAUSSURE, 2004) do manuscrito a ser analisado, Sofia aponta que "a ordem original das páginas e, por conseguinte, do texto, foi alterada” (2012, p. 38), assim como “a pontuação original do manuscrito foi frequentemente alterada", "as abreviações foram desenvolvidas, muitas vezes de maneira duvidosa” (2012, p.40) e que "a omissão de passagens rasuradas, vistas desde o prefácio, dá-se de maneira irregular" (p. 40). Além disso, Sofia afirma que "muito frequentemente, os editores omitiram a menção de títulos ou indicadores presentes no manuscrito" (2012, p. 40), que "as datas escritas por F. de Saussure em algumas folhas foram inexplicavelmente omitidas" (2012, p. 40) e que "em certos casos, os editores adicionaram termos que não aparecem no manuscrito” (2012, p. 40). Dessa forma, se se entende, junto de Silveira (2007), que "houve um trabalho na fundação da linguística e ele não se fez sem deixar só seu produto, mas também as marcas desse movimento" (p. 116), utilizar-se de uma edição que apaga as marcas materiais desse movimento seria, no mínimo, ingenuidade metodológica.

\footnotetext{
${ }^{13}$ Refere-se aqui aos Escritos de Linguística Geral como "Saussure (2004)", por entender-se que a obrabase, apesar de editada por Engler e Bouquet, deve ser creditada ao mestre genebrino.
} 
Por fim, além da apresentação de imagem dos trechos do manuscrito, tendo em vista deixar os procedimentos de leitura e interpretação do escrito claros para o leitor, opta-se por utilizar transcrição diplomática e traduzida dos trechos relevantes para análise, já que, para Grésillon (2007), esse tipo de transcrição "respeita fielmente a topografia dos significantes gráficos no espaço: cada unidade escrita figura no mesmo lugar da página que aquele do original" (p. 335). Trazê-la para as análises aqui apresentadas torna possível compartilhar aquilo que Saussure escreve e como ele o faz, sendo viável, inclusive, atentar para o que Silveira (2018) chama de rasuras "constitutivas da escrita”, já que essas podem nos dar acesso às marcas do pensamento saussuriano no que tange àquilo relativo às noções de sentido.

\section{O lugar do sentido na construção teórica (da dupla essência) da linguagem}

Além de entender como Saussure dialoga com a linguística feita por seus contemporâneos, para pesquisar o lugar que as noções de sentido têm dentro de um manuscrito, é fundamental compreender, como aponta Silveira (2007), que o trabalho do genebrino consiste em uma elaboração constante, passando por vários lugares. Dessa forma, o que é observado em suas elaborações não pode ser visto como linear, de modo que Saussure "não começou no comparatismo e terminou na sincronia”, também não iniciou "nas aulas e terminou na edição dessas por seus alunos" (SILVEIRA, 2017, p.145) e tampouco "começou nos anagramas e terminou na teoria do valor" (p. 145). Nesse sentido, tenta-se dar ênfase, aqui, ao manuscrito nele mesmo, apresentando-o e analisando-o conforme os objetivos antes expostos neste documento.

Com vistas a facilitar a leitura do manuscrito, além dos procedimentos da transcrição diplomática (cf. SILVEIRA, 2007; GRESILLION, 2017) e da tradução dos trechos considerados relevantes, fazem parte das convenções de transcrição deste trabalho o uso de colchetes - para apontar, nos períodos, a adição de incisos sinalizada em algum lugar no texto original - e o uso de parênteses com uma interrogação logo 
após uma palavra - para marcar dúvida em sua transcrição - ou com várias interrogações - para marcar a inteligibilidade de um termo manuscrito.

Começa-se, então, com um trecho do prefácio do documento manuscrito:

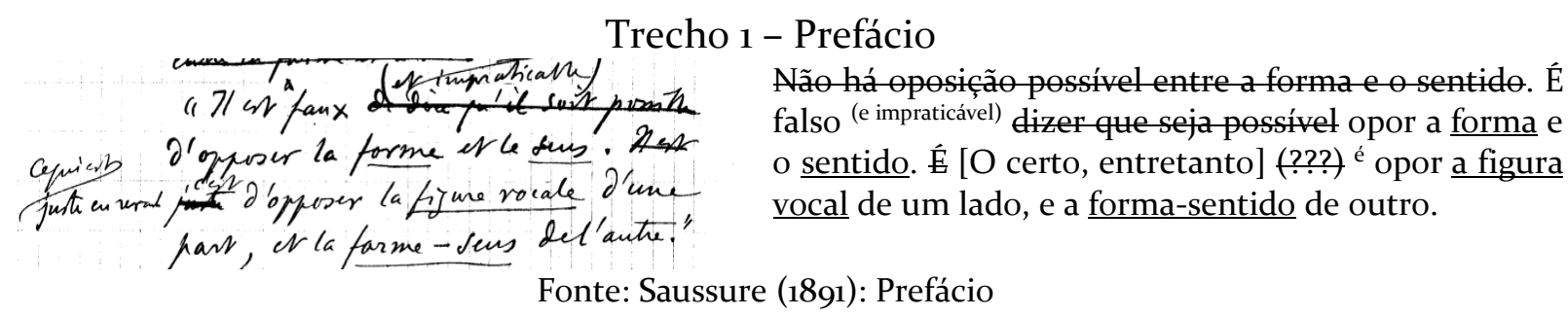

Em se pensando as considerações sobre o sentido desse trecho, já se vê algo interessante em questões terminológicas: não se opõem forma e sentido, mas figura vocal e forma-sentido. Ora, isso é pensar não apenas na oposição e na justaposição convencional dos elementos que constituem a língua, como faziam seus contemporâneos, mas propor uma análise que vai além disso. Nesse sentido, para Saussure, o sentido de um dado linguístico anda lado a lado com sua forma, não podendo ser dessa separado, como propõem Paul, Bréal e Whitney em seus trabalhos. O que se separa destes é apenas a figura vocal, ou seja, a produção individual de sons que serve como envelope a essa forma-sentido.

A ideia de figura vocal/forma-sentido é retomada na terceira página da parte $2 \mathrm{C}$ do manuscrito, completamente rasurada pelo linguista genebrino:

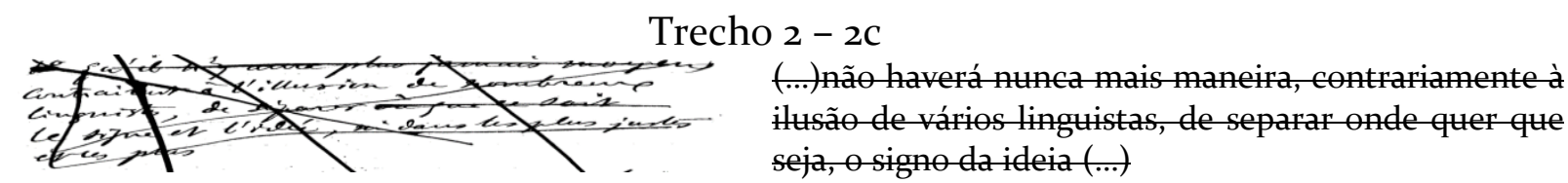

Fonte: Saussure (1891): 2C

Note-se, aqui, a flutuação terminológica de "signo", que, neste trecho (e ao longo do $E D L)$ significa "figura vocal". Além disso, vemos uma leve mudança na noção de figura vocal e forma-sentido. Esse último termo passa a ser compreendido simplesmente como ideia, o que permite a inferência de que uma ideia, em uma língua, está necessariamente 
ligada a uma forma e que essas são as responsáveis pelo sentido de um elemento linguístico. Essa elucubração vai adiante no trecho 2c:

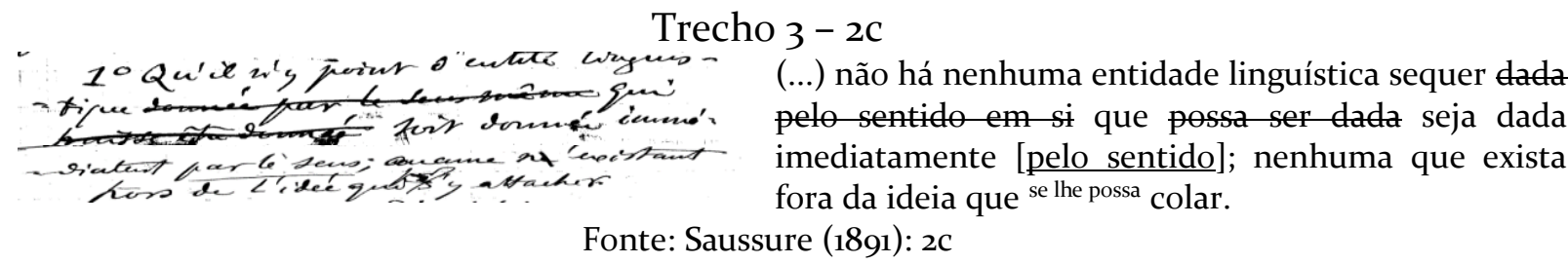

Veja-se que o sentido adquire um papel central na construção da teorização saussuriana, pois não há entidade que exista fora dele. No entanto, faz-se mister dar atenção ao trecho que afirma que tal entidade também não poderá ser dada pelo sentido nele mesmo ou imediatamente por esse. O que essa aparente contradição indica? Ora, aqui pode-se ler um Saussure que, mais uma vez, dialoga com a linguística feita em seu tempo e tem vistas a ir além dela. Em outras palavras, se uma entidade não pode ser tomada pelo seu sentido em si, esse objeto deve ser considerado não de uma maneira puramente psicológica, como o sentido individual que cada indivíduo atribui a algo, como descrito por Paul (1966) e visto como ponto comum pelo movimento dos neogramáticos. Ainda sobre isso e, mais uma vez, dialogando e indo além da linguística de seu tempo, Saussure afirma, no trecho za, que

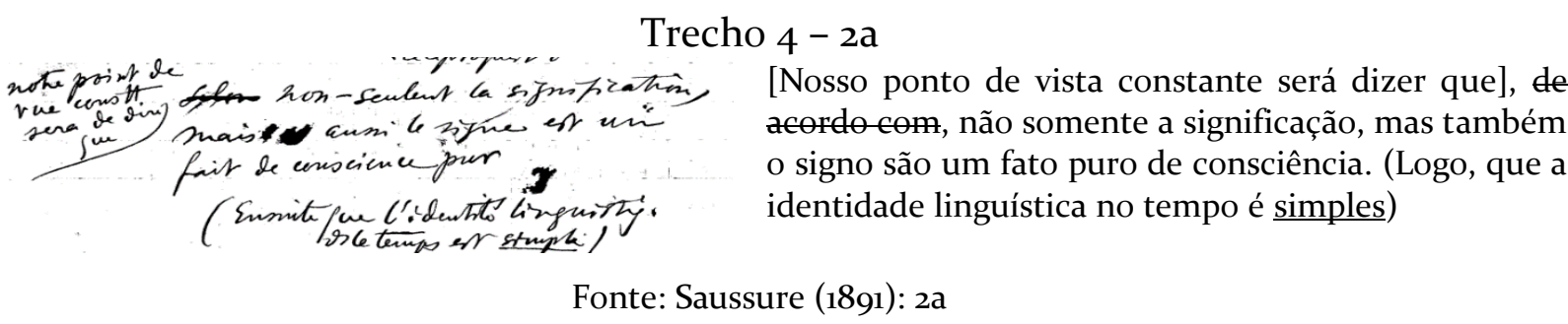

Em um primeiro ponto, afirma-se que o signo (figura-vocal) e a significação - de novo, vê-se a oposição entre esses dois elementos - são algo relacionado à consciência. Essa consciência, no entanto, não é aquela dos neogramáticos, estritamente psicologizantes, mas aquela de uma comunidade linguística. Aqui, vemos ecos do pensamento de Whitney (2010) e Bréal (1992), quando esses afirmam que a mudança no sentido das palavras se dá e se estabiliza dentro de uma comunidade de falantes. 
Em um segundo ponto, define-se a identidade linguística no tempo como algo simples. A leitura dessa afirmação passa pela sublinha feita na palavra "simples". Essa ênfase não é à toa. Afinal, se a significação é um "fato puro de consciência" e isso significa dizer que ela só se dá dentro de uma comunidade de falantes, essa "consciência” só pode ser cientificamente observada em um ponto específico no tempo. Logo, a entidade linguística ser "simples" no tempo quer dizer que ela só pode ser verificada em uma perspectiva temporal específica, limitada, e não comparativa, como se compreendia nos séculos XVIII e XIX. Portanto, entender que "a entidade linguística no tempo é simples”, é pensar em um objeto científico dado por uma significação (já que esse não pode existir sem ela) em um determinado espaço temporal. Não basta aqui entender os elementos que fazem parte da língua como parte da história, como Paul, Bréal e Whitney, mas vêla em um contexto específico, em que a comparação de dados linguísticos e históricos não acrescenta à descrição linguística da "consciência” dos falantes em um dado momento.

A partir dessas noções que dialogam e que vão além dos estudos da linguagem feitos nos séculos XVIII e XIX, Saussure começa a delimitar algo que aparecerá, mais tarde, em sua obra póstuma (SAUSSURE, 1970): as questões do sentido e da forma como intimamente ligadas ao valor. Eis o que o mestre coloca no trecho $3 f$ :

Trecho $4-3 f$ 


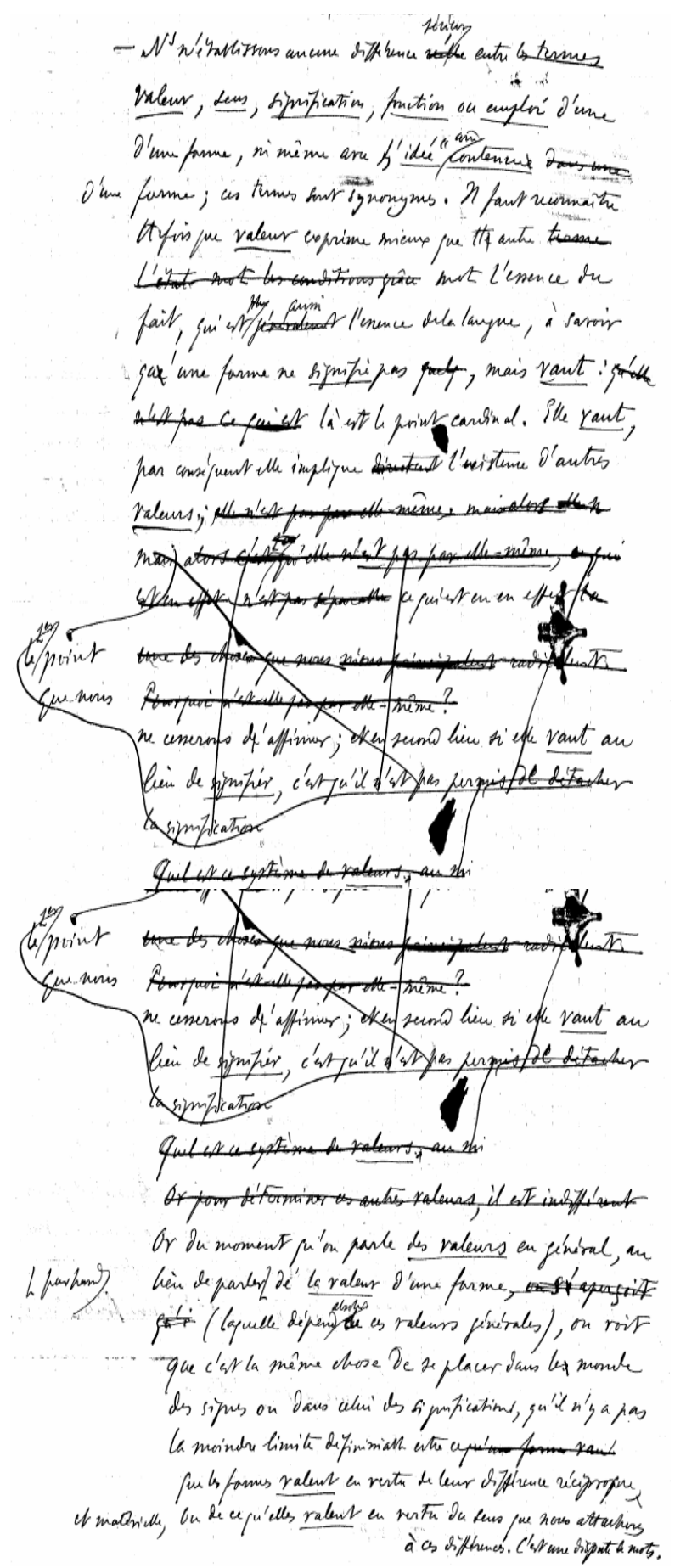

Nós não estabelecemos nenhuma diferença real ${ }^{\text {séria }}$ entre os termos valor, sentido, significação, função ou emprego de uma de uma forma, nem mesmo a

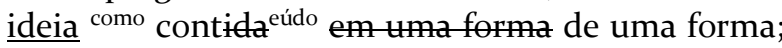
estes termos são sinônimos. Deve-se reconhecer, de qualquer maneira, que valor exprime melhor que qualquer outro termo- estado palavra as condições graças palavra a essência do fato, que é (???) normalmente também a essência da língua, a saber que uma não significa alg, mas vale: que ela não é aquilo que este é o ponto cardeal.

Ela vale, por consequência, ela implica diretamente a existência de outros valores; ela não existe nela mesma, mas então ela não é mais $\left[0-10^{\circ}\right.$ ponto que nós] então que ela não é não existe nela mesma de quem com efeito não é separável aquilo que é com efeito uma das coisas que nós principalmente radicalmente

Por que ela não existe nela mesma?

[O1..0 ponto que nós] não cessaremos de afirmar [ ] ; e em segundo lugar, se ela vale em detrimento

de significar, é porque não é permitido a ela deslocar-se da significação.

Qual é este sistema de valores, na melh

Ora, por determinar outros valores, é insuficiente(?)

Ora, a partir do momento em que falamos de valores em geral, em vez de falar [acidentalmente] do valor de uma forma, percebe-se que (aquele que depende absolutamente de seus valores gerais), vemos que é a mesma coisa que se colocar nos mundos dos signos ou naquele das significações, que não há o menor limite definível entre aquilo que uma forma vale o que as formas valem em virtude de sua diferença recíproca [e material] ou daquilo que elas valem em virtude do sentido que damos a essas diferenças. É uma disputa de palavras.

Fonte: Saussure (1891): $3 \mathrm{f}$

Além da grande quantidade de rasuras nesse trecho, algo que chama a atenção é o fato de Saussure estabelecer sinonímia entre os termos "sentido", "significação", "função" ou "emprego de uma forma" com o termo "valor". O genebrino ainda coloca que o valor engloba a ideia ou o conteúdo de uma forma. Assim, a noção de ideia e de sentido reconfiguram-se no pensamento saussuriano, sendo colocadas como valor, já 
que "uma forma não significa, mas vale". Afinal, o que significa o fato de uma forma ter valor em vez de significar?

Essa diferenciação terminológica é também uma virada epistemológica, já que se deixa de empregar termos relativos a uma abordagem puramente psicológica e abstrata dos fatos linguísticos para entendê-los dentro de um jogo de relações com outros de mesma natureza, sendo seu sentido dado a partir daí. Assim, nota-se mais uma vez o diálogo do mestre com a linguística comparativa, que se preocupava com o significado de uma palavra apenas em comparação com a sua história. Indo além disso, o genebrino concebe que o sentido de um elemento linguístico não se dá em comparação com a sua história ou é dado de antemão, mas sim só pode ser compreendido ao se comparar um elemento com outro. Em outras palavras, um elemento só pode ter sentido (e, por conseguinte, existir em uma língua) em relação a outro, como pode-se ler nos trechos rasurados.

Nos parágrafos rasurados por Saussure, também pode-se ler que, se uma forma "vale em detrimento de significar, é porque não é permitido a ela deslocar-se da significação”. Embora o linguista pense em significação e valor como termos sinônimos, vê-se aqui a tentativa de estabelecer uma diferença teórica, ainda que sutil. Uma forma não pode se deslocar de sua significação porque é a união da forma com a ideia, em termos recorrentes na época de Saussure e retomados por ele, que formará a oposição impossível colocada pelo genebrino no prefácio do manuscrito. No entanto, sua tomada filosófica vai mais além, pois o valor se dará quando as significações ou as formas forem diferentes entre si e apenas por isso.

É interessante retomar aqui que o termo "valor" já aparecia no Ensaio de Semântica, de Bréal ([1897] 1992, p. 104), para designar o lugar que certo elemento ocupava em um sintagma e como isso poderia mudar o sentido "original" desse elemento. Se essa noção for comparada com a saussuriana, pode-se notar certa semelhança, visto que existe uma oposição dentro de sintagmas, uma vez que cada elemento neles disponíveis ocupa uma função e, portanto, é diferente dos demais. Nesse sentido, teríamos uma oposição de valores presentes e vistos quanto à sua significação em ambos os autores. Contudo, as diferenças que compõem o valor em Saussure vão 
além daquilo que se vê em um sintagma, conforme se vê no subcapítulo $3 \mathrm{~g}$ do manuscrito:

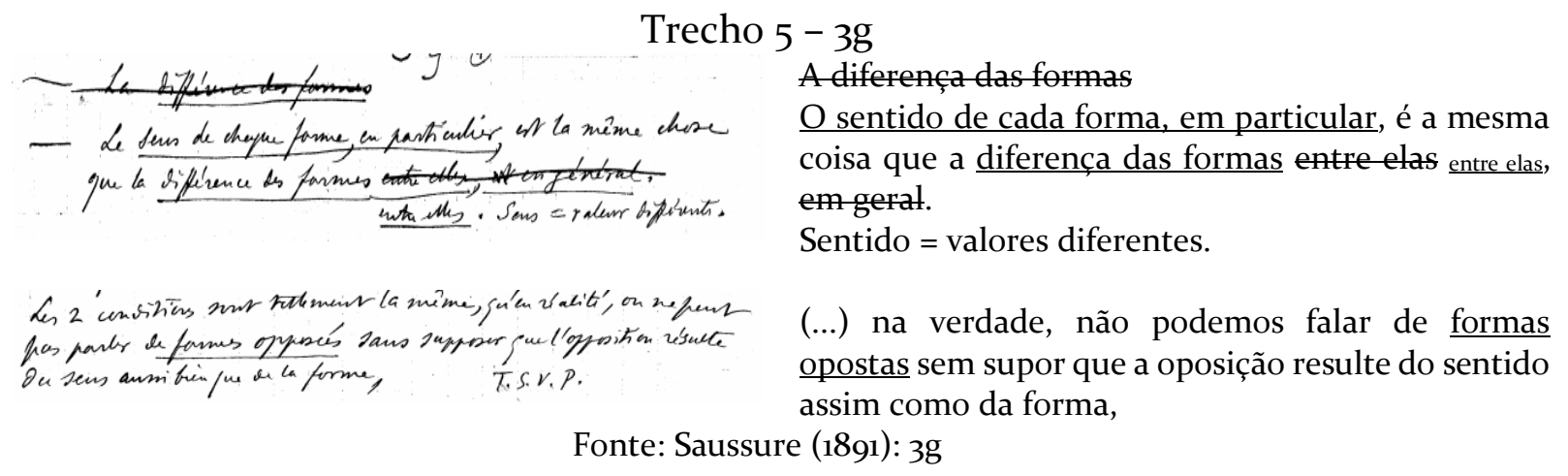

Nesse trecho, vê-se uma definição clara de que o sentido das formas e, portanto, seu valor se dá por sua diferença. Em um primeiro momento, isso não parece ser muito diferente do que fora afirmado anteriormente. No entanto, uma análise mais cuidadosa permite prestar atenção à seguinte passagem: "não podemos falar de formas opostas sem supor que a oposição resulte do sentido assim como da forma”. Ora, que a oposição resulta e é o que caracteriza o sentido já se viu anteriormente e se pode, inclusive, recuperar da semântica brealina. Todavia, considerar que essas diferenças estão também no plano da forma faz o pensamento teórico ir além daquilo já estabelecido.

Considere-se o seguinte: em condições normais de fala, pode-se emitir apenas um som, um morfema ou uma palavra por vez. Tomem-se todos esses como "formas". Portanto, pensar em uma oposição de uma forma em detrimento da outra não só faz sentido no plano da sintaxe, quando uma forma se relaciona com outra a fim de formar um todo significativo, mas principalmente uma forma concorre com outra em um plano virtual. Isso explica e permite ler o trecho $2 \mathrm{c}$ do manuscrito com menos inocência teórica. Nele se coloca o que segue:

Trecho $6-2 \mathrm{C}$

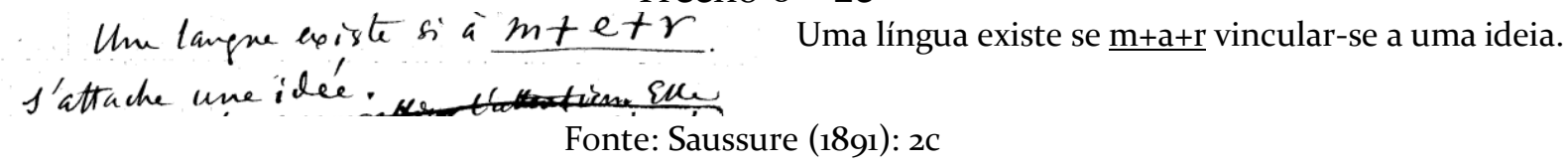


A palavra formada pela união dos sons $/ \mathrm{m} /+/ \mathrm{a} /+/ \mathrm{r} /$ existe por vincular-se a uma ideia. Ou seja, não se pode separar uma figura vocal (os sons em si) daquilo que eles representam dentro da língua. Essa palavra existe em uma língua não por essa ideia representar algo no mundo, pois quaisquer outras combinações de sons poderiam fazêlo. Mais do que isso, essa palavra existe porque as formas $/ \mathrm{m} /+/ \mathrm{a} /+/ \mathrm{r} /$ se juntam em uma cadeia sonora que permite ao falante proferi-la e que essa cadeia sonora é aceita pela comunidade em que tal sujeito vive naquele momento como algo que tem uma significação. Mais ainda, e é aqui que se vê um encaminhamento do constructo teórico que aparecerá mais tarde no Curso de Linguística Geral (SAUSSURE, 1970), a palavra "mar" existe por não ser, por exemplo, a palavra "bar" (em que a forma sonora /b/ concorre com a /m/), a palavra "par" (em que a forma sonora /p/ concorre com a /m/), a palavra "mal" (em que a forma sonora /r/ concorre com a /1/), etc. Dito de outro modo, a palavra significa por não ser outra e suas formas significam por não serem outras, de modo que as formas que não são - e que também significam por não o serem - se apresentam virtualmente, enquanto a forma que é, presencialmente.

\section{Considerações finais: o sentido em (re)visão constante}

Este trabalho investigou um dos possíveis lugares dados à noção de sentido na elaboração da teoria saussuriana no final do século XIX, tomando como base para fazêlo os primeiros seis capítulos do manuscrito De l'Essence Double du Langage (SAUSSURE, 1891). Embora o termo "sentido" apareça esporadicamente no corpus aqui escolhido, notou-se que outras noções relativas a esse eram frequentes na escrita saussuriana. Várias foram as vezes em que foi possível deparar-se com as palavras "ideia”, “significação”, “pensamento”, etc. Dessa forma, desde o prefácio do documento analisado, já se vê que o sentido - em sua concepção mais lata, a ideia - está presente e é fundamental para o pensamento da língua. Nessa parte, a forma anda sempre junto com a ideia, e ambas se opõem à figura vocal. 
No entanto, conforme se leem as páginas escritas pelo mestre genebrino, começase a ver que a significação ganha o lugar da ideia e, finalmente, que o valor ganha o lugar da significação, sendo essa a noção que Saussure utiliza para designar, em última análise, os jogos e as combinações de sentido em uma língua. Para ele, um valor de um elemento linguístico só pode ser se esse o for negativamente. Em outras palavras, o sentido de um elemento na língua só se dá por ser o que os outros não são, seja em uma relação direta com as outras formas-sentido no plano sintagmático, seja em relação com as outras formas-sentido que não foram selecionadas pelo falante no momento de sua fala.

Ainda sobre isso, vale ressaltar que o linguista suíço considerava as unidades da língua como algo determinado pelo tempo de forma simples. Ou seja, uma forma, e, consequentemente, o sentido, só podem ser analisados e vistos pelo linguista no tempo em que viraram língua por intermédio de um sujeito e de uma comunidade de sujeitos falantes. Depreende-se, pois, que o valor/sentido de uma forma linguística é sempre situado, ou seja, dá-se apenas em determinado tempo dentro de uma comunidade falante, não podendo ser analisado apenas em sua história ou por aquilo que deveria ser por suas raízes. Ele sempre será dado no agora do falante e em relação a todas as outras formas linguísticas de uma mesma língua.

Apesar da genialidade e da novidade das concepções sobre a língua, seus elementos e, até implicitamente, sobre o fazer do linguista abordadas no manuscrito, há autores que defendem que elas já haviam sido gestadas e mesmo desenvolvidas pela linguística dos séculos XVIII e, especialmente do século XIX'14. As análises apresentadas, entretanto, não corroboram essa tese. Vê-se que alguns termos como "sentido" e "valor" ou mesmo as noções de uma coletividade linguística aparecem nos autores aqui explorados. No entanto, suas concepções são diferentes e, de maneira geral, estão ainda ligadas ao estudo histórico e comparativo das línguas e não a uma teorização maior sobre a língua de maneira geral.

\footnotetext{
${ }^{14}$ Não é o objetivo deste artigo entrar a fundo nessas questões ou apontar paternidade de conceitos, como tenta fazer Bagno (2021). Sobre isso, acredita-se que a ciência está sempre em evolução e que, muitas vezes, os termos tomados em um trabalho, como coloca Milner (1989), mesmo que sejam iguais, podem corresponder a construções teórico-metodológicas completamente diferentes.
} 
Assim, a partir das análises dos primeiros “capítulos" do manuscrito De l’Essence Double du Langage e da comparação com a prática linguística dos séculos XVIII e XIX, infere-se que Saussure parecia estar envolvido com a elaboração de um constructo teórico que colocasse as questões de sentido como centro de sua concepção da linguagem e da análise linguística. Dessa forma, ao vincular as análises linguísticas à observação de unidades da língua que só podem existir se estiverem em relação entre si e entre o que poderiam ser, pode-se dizer que Saussure respectivamente, parte do que vinha sendo desenvolvido por seus contemporâneos, mas rompe com tal tradição, especialmente ao pensar uma perspectiva sincrônica para o sentido e não dar lugar relevante à sua evolução temporal em relação a uma forma dentro de sua elaboração teórica, como era o costume entre os comparatistas e os neogramáticos. E esse rompimento com a tradição aparece bem marcado no texto do genebrino, em especial naquilo que foi riscado ou suprimido.

Nesse sentido, ao se analisarem as inúmeras rasuras presentes no texto saussuriano, vemos que elas indicam titubeios no pensamento de Ferdinand de Saussure ao formular os fundamentos de uma ciência da língua. Isso se dá pelo fato de o genebrino rasurar várias sentenças em que afirmava algo categoricamente, e/ou em que parecia afirmar algo completamente novo em relação a seus contemporâneos, como pensar a língua como um sistema de valores puros ou entender que o sentido de uma palavra apenas pode se dar a partir disso. Além disso, vê-se que Saussure retoma sua escrita várias vezes, reformulando-a, colocando incisos, substituindo expressões adverbiais fortes por outras.

\section{Referências}

BAGNO, M. Excurso crítico para uma leitura incontornável. In: SAUSSURE, F. de. Curso de Linguística Geral. 1 ed. São Paulo: Parábola, 2021.

BENVENISTE, É. La forme et le sens dans le langage. In: BENVENISTE, É. Problèmes de Linguistique Générale 2. 1ำ edição 1967. Paris: Éditions Gallimard, 2017. 
BOUQUET, S. Saussure's unfinished semantics. In: SANDERS, C. (org.) The Cambridge Companion to Saussure. Cambridge: CUP, 2004.

BRÉAL, M. Ensaio de Semântica: ciência das significações. Tradução de Aída Ferraz et al. Coordenação e revisão técnica de tradução de Eduardo Guimarães. 1ª edição 1897. São Paulo: Pontes, 1992.

CÂMARA JR, J. M. História da Linguística. Edição revista e comentada. Revisão e comentários de Valdir do Nascimento Flores e Gabriel de Ávila Othero. 1. a ed. Petrópolis: Vozes, 2021.

CHIDICHIMO, A; GAMBARARA, D. Trois chapitres de 'L'Essence Double du Langage'. Cahiers Ferdinand de Saussure: revue suisse de linguistique générale, Genève: Librairie Droz, n. 61, 2008.

COELHO, M. Ferdinand de Saussure: entre a língua e as línguas. Tese (Doutorado) Programa de Pós-Graduação em Estudos Linguísticos, Universidade Federal de Uberlândia: Uberlândia, 2019.

DE LEMOS, et al. Le saussurisme en Amérique Latine au XXe siècle. Cahiers Ferdinand de Saussure: revue de linguistique générale. Genebra: Librairie Droz, n. 56, 2003.

DEPECKER, L. Compreender Saussure a partir dos Manuscritos. Tradução de Maria Ferreira. Petrópolis: Vozes, 2012.

FLORES, V. Problemas Gerais de Linguística. 1 ed. Petrópolis: Vozes, 2019.

GRÉSILLON, A. Elementos de Crítica Genética: ler os manuscritos modernos. Porto Alegre: Editora da UFRGS, 2007.

GUIMARÃES, E. Os Limites do Sentido: um estudo histórico e enunciativo da linguagem. Campinas: Pontes, 2005.

MILNER, J-C. Introduction à une Science du Language. Paris: Éditions du Seuil, 1989.

NORMAND, C. Saussure. 1aㅡ edição 200o. São Paulo: Estação Liberdade, 2009.

PAUL, H. Princípios Fundamentais da História da Língua. Tradução de Maria Luiza Schemann. 1ª edição 1886 Lisboa: Fundação Calouste Gulberkian, 1966.

SAUSSURE, F. de. De l'Essence Double du Langage. Manuscrito. S.1.: 1891.

SAUSSURE, F. de. Curso de Linguística Geral. Tradução de Antônio Chelini, José Paulo Paes e Izidoro Blikstein. 1ª edição 1916. São Paulo: Cultrix, 1970. 
SAUSSURE, F. de. Escritos de Linguística Geral. BOUQUET, Simon; ENGLER, Rudolf (org. e Ed.). Tradução de Carlos Augusto Leuba Salum e Ana Lúcia Franco. 1ae edição 2002. São Paulo: Cultrix, 2004.

SILVEIRA, E. Saussure à brasileira: estatuto epistemológico do Curso de Linguística Geral nos manuais publicados entre 1930 e 1980. In: FARACO, C. A. (org.). O efeito Saussure: cem anos do Curso de Linguística Geral. São Paulo: Parábola, 2016.

SILVEIRA, E. A produção teórica de Saussure em dois manuscritos do fim do século XIX. Revista Investigações, v. 26, n. 2, p. 01-31, 2013.

SILVEIRA, E. As Marcas do Movimento de Saussure na Fundação da Linguística. São Paulo: Mercado de Letras, 2007.

SILVEIRA, E. Ensaio sobre a variedade das rasuras em alguns manuscritos de Saussure. D.E.L.T.A., n. 34, v. 3, p. 835-859, 2018.

SOFIA, E. Quelques problèmes philologiques poses par l'œuvre de Ferdinand de Saussure. Langages. v. 185, p. 35-50. Paris: Armand Colin, 2012.

WHITNEY, W. D. A Vida da Linguagem. Tradução de Márcio Alexandre Cruz. $\mathbf{1}^{\mathrm{a}}$ edição 1875. Petrópolis: Vozes, 2010.

Recebido em 26/07/2021. Aprovado em 25/11/2021. 